\title{
“Crispy" Blackberry Genotypes: A Breeding Innovation of the University of Arkansas Blackberry Breeding Program
}

\author{
Alejandra A. Salgado ${ }^{1}$ and John R. Clark \\ Department of Horticulture, University of Arkansas, 316 Plant Science \\ Building, Fayetteville, AR 72701
}

Additional index words. Rubus, flesh texture, firmness, color reversion, postharvest handling

\begin{abstract}
The University of Arkansas (UA) blackberry breeding program began in 1964, with the aim to provide high-quality fruit to the fresh market industry. One of the important traits for successful blackberry (Rubus subgenus Rubus Watson) postharvest handling is flesh firmness, so developing cultivars with high firmness is a top priority for the fresh market blackberry breeding programs across the world. In particular, the Arkansas blackberry program has a wide range of genotypes with exceptional firmness characteristics, including fruit with a unique crispy texture and firmness. During 2013 and 2014, fruit firmness measurements were done on 15 Arkansas genotypes including those with crispy and noncrispy textures. Firmness measurements consisted of fruit compression, skin drupelet penetration, and receptacle penetration. Confocal photos were taken on sections of berries of a subset of crispy and noncrispy genotypes, and color reversion was evaluated among these genotypes after storage. Compression force values differentiated crispy and noncrispy genotypes, with average values of 11.8 Newton $(N)$ and $8.0 \mathrm{~N}$, respectively. Drupelet penetration force was also higher for crispy genotypes averaging $0.23 \mathrm{~N}$ and noncrispy $0.15 \mathrm{~N}$; similarly, receptacle penetration force averaged $0.20 \mathrm{~N}$ for crispy and $0.18 \mathrm{~N}$ for noncrispy genotypes. Visual inspection of fruit tissue revealed that drupelet mesocarp cells and receptacle cells and cell walls of crispy genotypes maintained their structure during ripening and did not break apart, whereas noncrispy genotypes did not maintain their structure and cellular integrity. Color reversion is a postharvest disorder in which drupelets of blackberry fruits turn red after being black at harvest. Therefore, it has a negative impact for growers, shippers, and consumers. After storage at $5{ }^{\circ} \mathrm{C}$ for 7 days, crispy genotypes expressed low levels of reversion compared with noncrispy genotypes. For crispy genotypes, $13.2 \%$ of drupelets developed color reversion, whereas a $41.0 \%$ developed this disorder in noncrispy genotypes, implying a better postharvest potential of this texture.
\end{abstract}

Production of fresh market blackberries in the United States has expanded greatly compared with most of the world, especially in California along with new commercial production in Georgia, North Carolina, Arkansas, and Texas (Clark and Finn, 2014). This expansion is due to several factors, including an increase in demand and resulting consumption in the United States and Europe (Clark and Finn, 2014). In 2005, Europe had 7692 ha of blackberries in commercial production, and Serbia was the leading country with $69 \%$ of the area in Europe (Strik et al., 2007). Serbia continues as one of the top blackberry producers in the world with more than 5000 ha planted (Clark and Finn, 2014), although this production is primarily for processing. Mexico leads the world with over 6500 ha in production, almost all production for the fresh market and export (Clark and Finn, 2014).

The blackberry industry is in expansion and reasons for this phenomenon are several,

Received for publication 10 Dec. 2015. Accepted for publication 22 Mar. 2016.

1Corresponding author. E-mail: asalgado@uark.edu. but include that blackberry is a new crop in many areas of the world; new blackberry cultivars ship better allowing for extension of the harvest and maturity season; fruit quality is improved in newer cultivars; blackberry fruits have high levels of anthocyanins and antioxidants providing for increasing appeal to consumers; and longer-season production allows for year-round marketing enhancing grower, packer, and processor profitability (Clark and Finn, 2014; Clark et al., 2007).

The quality of fruits for the fresh market is determined largely by how the genotype responds to storage and handling from the day of harvest until purchased and eaten by the consumer (Finn and Clark, 2012). Blackberries have been considered as one of the most difficult fruits to ship due to postharvest softening and leakage during handling (Clark, 2005). Blackberry fruit firmness was once suggested to be an intractable trait, meaning that it is a difficult character to improve in breeding. Firmness varies with cultivar, ripeness stage, and storage duration (Clark, 2005; Perkins-Veazie et al., 1996).

Generally in fruits, firmness is related to modifications of the polysaccharide components of the primary cell wall and middle lamella during fruit ripening, resulting in a weaker fruit structure at the end of the ripening process (Brummell, 2006; Winkler et al., 2015). Alterations in the bonding between polymers along with degradation of polysaccharides can cause an increase in cell separation, softening, and swelling of the cell wall (Brummell, 2006). These alterations, combined with changes in cell turgor, cause fruit softening and textural changes in fruits (Brummell, 2006). Blackberries increase their pectin solubility activity during ripening (Brummell, 2006). In apples (Malus $\times$ domestica Borkh.), ripening is accompanied by decreasing strength of the middle lamella, resulting in reduced intercellular adhesion and increased cell separation under stress (Atkinson et al., 2012). A suppression of the gene that promotes polygalacturonase (PG) activity resulted in firmer 'Royal Gala' apples due to different distribution of pectins along with increased integrity of the middle lamella (Atkinson et al., 2012). Also, in the PG-suppressed genotypes, cells in the hypodermal layers of the fruit below the cuticle remained densely packed (Atkinson et al., 2012).

An important postharvest disorder affecting blackberry fruit destined for the fresh market is color reversion (also called reddening or red drupelet; Clark and Finn, 2011). Affected drupelets of blackberry fruits turn red, often during cold storage or when exposed at room temperature after being in cold storage (Clark and Finn, 2011; Finn and Clark, 2012). In a mature fruit cell, $\approx 90 \%$ of the volume is occupied by the vacuole, a cell organelle that is dynamic and multifunctional and provides the primary site of macromolecule storage and turnover (Fontes et al., 2011). The vacuole accumulates sugars, aromas, flavors, ions, and water; all these compounds are transported across the tonoplast (vacuole membrane) by a specific transporter protein (Fontes et al., 2011).

Retention of black color can be selected for in breeding, but it cannot be determined in the field. Therefore, postharvest evaluations must be done to verify if resistance to reversion is present (Clark and Finn, 2011). The UA blackberry breeding program, with a focus on postharvest quality of fruits for successful postharvest storage for the fresh market, began postharvest evaluations in 2008 to characterize postharvest traits of advanced breeding selections (Clark and Perkins-Veazie, 2011).

Crispy fruit with high firmness were first observed in the UA blackberry breeding program several years ago on a floricanefruiting, thorny selection. Since that time, this texture trait has been advanced to improved selections with the aim to transfer the crispiness into improved seedlings and resulting selections with increased yield, fruit size, fruit flavor, and primocane fruiting. Two of these, A-2453 and A-2454, are believed to hold the most promise for use in breeding for this trait. These crispy genotypes show improved postharvest performance compared with previously released cultivars from the 
breeding program. They maintain the high firmness observed in the field and after storage, and also show reduced color reversion (drupelets developing red color) after $7 \mathrm{~d}$ of cold storage (J.R. Clark, unpublished data).

The objectives of this study focused on characterization of crispy and noncrispy genotypes including compression and penetration forces in different tissues of the fruit. Also, analysis of cell structure of drupelet and receptacle tissue of crispy and noncrispy genotypes was conducted to reveal physical aspects contributing to the unique texture.

\section{Materials and Methods}

Plant material. All fruit collection and firmness measurements were conducted at the UA Fruit Research Station (FRS), Clarksville [west-central Arkansas, lat. $35^{\circ} 31^{\prime} 58^{\prime \prime} \mathrm{N}$ and long. $93^{\circ} 24^{\prime} 12^{\prime \prime}$ 'W; U.S. Department of Agriculture (USDA) hardiness zone 7a (USDA, 2012); soil type Linker fine sandy loam (Typic Hapludult)]. Confocal image analysis for cell structure analysis was done at UA, Fayetteville campus. Blackberry plants were grown with cultural components including annual routine plant management practices such as fertilization, weed and pest control, and irrigation. All plantings received a single application of fungicide at budbreak for control of anthracnose [Elsinoë veneta (Burkh.) Jenkins] (Smith, 2016). Insecticides labeled for commercial use in Arkansas were used for spottedwing drosophila (Drosophila suzukii Matsumura) control. All plots were irrigated as needed using overhead sprinkler irrigation. Harvest period was between 12 June and 30 June in 2013, and between 9 June and 3 July in 2014.

Genotypes used in this study were crispy (A-1790, A-2218, A-2453, and A-2454), and noncrispy ('Prime-Ark ${ }^{\circledR} 45$ ', 'Natchez', 'Osage', 'Ouachita', A-1960, A-2252, A-2297, A-2416, A-2417, A-2418, and A-2428). Tested crispy genotypes corresponded to the entire crispy pedigree currently present in the Arkansas program (A-2453 and A-2454 are siblings, A-2218 is parent of both selections, and A-1790 is parent of A-2218). Tested noncrispy selections corresponded to selections used in crossing with A-2453 and A-2454. Also, released cultivars were included in the noncrispy group.

Each genotype was harvested into $260-\mathrm{g}$ clamshells (FormTex Plastics Corp., Houston, TX). Genotypes were harvested between two and six times per season, depending on fruit availability. Some selections were only available in one single plot at the research station and sometimes it was difficult to obtain high-quality fruit to evaluate more than two times per season. However, some selections were present in multiple plots and they had a higher amount of high-quality fruit available to harvest more than two times per season. In 2013, two clamshells and an additional 10 berries were harvested at each harvest date for each genotype. The fruits of one clamshell (randomly selected) were used to measure fruit compression (15-20 fruits) and the other clamshell was used to measure drupelet penetration (10 fruits) and receptacle penetration
(10 fruits). The additional 10 berries were used for reversion measurements after storage for $7 \mathrm{~d}$ at $5{ }^{\circ} \mathrm{C}$. In 2014, two clamshells were harvested at each harvest date and used to measure firmness at harvest day (day 0), and an extra clamshell was harvested to measure color reversion after $7 \mathrm{~d}$ of cold storage at $5{ }^{\circ} \mathrm{C}$ (clamshells were stored in a closed plastic tub within the refrigerator to avoid dehydration caused by the excessive air circulation). For fruit firmness at harvest day, these same measurement procedures of 2013 were followed in 2014. In the case of color reversion, all fruit in the clamshell (15-20) were evaluated.

Phenotypic evaluation. Fruit firmness was measured using an iCon Texture Analyzer (Texture Technologies Corp., Hamilton, MA) using two different methodologies:

1. Compression: Fruit compression was performed by placing individual fruits horizontally on a flat surface using a cylindrical and plane probe of 7.6$\mathrm{cm}$ diameter. Each fruit was compressed $5 \mathrm{~mm}$.

2. Penetration: Each fruit was cut in half longitudinally. One half was used for drupelet penetration and the other half to measure the receptacle firmness. Drupelet skin firmness was assessed using a probe of $1-\mathrm{mm}$ diameter. For this, three drupelets of similar shape and size were used per berry. Receptacle penetration was measured using a probe of $1-\mathrm{mm}$ diameter in the middle of the receptacle. For drupelet skin penetration and receptacle penetration, fruits were penetrated $1 \mathrm{~mm}$.

In 2014, fresh tissue of individual tori and drupelets of two crispy genotypes (A-2453 and A-2454) and two noncrispy genotypes ('Natchez' and 'Shawnee') were analyzed for fruit structural differences. Of the two noncrispy cultivars, Natchez, an industry standard with good firmness (Clark and Moore, 2008 ) is considered substantially firmer than 'Shawnee' (Perkins-Veazie et al., 2000). 'Shawnee' was added to the fruit structure analysis, because it is a soft-fruited older cultivar from the Arkansas program (images of A-2454 and 'Shawnee' are not shown). Berries were hand-sectioned with a razor blade into thin layers and mounted on a microscope slide with a cover slip. Slides were examined with $\times 20$ magnification with a confocal microscope (Nikon Eclipse 90i; Nikon Instruments Inc., Melville, NY) to examine cellular consistency. Photos were taken immediately after placement with a mounted camera (Ecos Rebel T2i; Canon USA Inc., Melville, NY) and analyzed with NISElements AR 3.2 software (Nikon Instruments Inc.) to allow evaluation of cellular differences among the genotypes.

Color reversion after 1 week of cold storage at $\approx 5{ }^{\circ} \mathrm{C}$ was evaluated in 2013 and 2014. All genotypes indicated in the plant material section were included in this evaluation with the exception of noncrispy genotypes
A-2416 and A-2418 (due to low fruit availability). For color reversion evaluation, each fruit was categorized using the following multinomial color reversion scale in which the levels were "none" (no red drupelets after cold storage in each berry), "some" (one to three red drupelets after cold storage in each berry), or "too many" (four and more red drupelets after cold storage in each berry).

Data analysis. Fruit compression force, skin drupelet penetration, and receptacle penetration were subjected to an analysis of variance (ANOVA) in which sources of variation were year (2013 and 2014) and texture (crispy and noncrispy). The PROC GLIMIX procedure was used (SAS ${ }^{\circledR}$ 9.4; SAS Institute Inc., Cary, NC). Least square means test was performed for mean comparisons $(P \leq 0.05)$ for better estimations of significant differences due to the unbalanced design. For this test, means were estimated from a linear model and adjusted to the number of observations, making the means less sensitive to missing data and better estimates of population means. For color reversion, data were subjected to ANOVA in which sources of variation were year (2013 and 2014) and texture (crispy and noncrispy). The PROC GLIMIX procedure was used for the ANOVA test. In this case, a multinomial distribution was used and the cumulative probability of a genotype to be in one of the three levels of color reversion was estimated ("none," "some," or "too many") (SAS $\left.{ }^{\circledR} 9.4\right)$.

\section{Results and Discussion}

Fruit firmness. A significant year (2013 and 2014) by texture (crispy and noncrispy) interaction was found for all force measurements $(P \leq 0.05)$. This indicated that different environmental conditions for both years likely affected firmness and this was reflected in all three types of firmness measurements. As in other fruits, such as apple and red raspberry (Rubus idaeus L.), firmness is a quantitative trait that is challenging to improve (Clark, 2005; Iwanami et al., 2008; Stephens et al., 2012).

In examining year by texture effects, compression values ranged from a high of $13.3 \mathrm{~N}$ for the crispy category in 2014 to $8.2 \mathrm{~N}$ for noncrispy in 2013, and $10.2 \mathrm{~N}$ for crispy in 2013 to $7.7 \mathrm{~N}$ for noncrispy in 2014 (Table 1). When comparing within-texture means among years, crispy values were different, with the 2013 value of $13.3 \mathrm{~N}$ and in 2014, $10.2 \mathrm{~N}$ (Table 1), whereas noncrispy means among years were also different ( 8.2 and $7.7 \mathrm{~N})$. In 2013 and 2014, values of skin drupelet penetration force of crispy texture were higher than noncrispy (Table 1). Skin drupelet penetration force value for within-crispy texture in 2013 was significantly higher than in 2014 (0.29 and $0.18 \mathrm{~N}$, respectively); also, drupelet skin penetration force within the noncrispy texture group was higher in 2013 compared with 2014 ( 0.17 and $0.12 \mathrm{~N}$, respectively) (Table 1). In 2013, the mean of receptacle penetration force of crispy texture was higher than noncrispy texture, but in 2014, they were not significantly different (Table 1 ). 
Table 1. Least square interaction means of compression force, skin drupelet penetration force, and receptacle penetration force of years (2013 and 2014$)$ by texture (crispy and noncrispy) on the day of harvest. Crispy texture means are averages of four genotypes, and noncrispy texture means are averages of 11 genotypes.

\begin{tabular}{|c|c|c|c|c|c|c|c|c|c|c|c|c|}
\hline \multirow{3}{*}{$\frac{\mathrm{Yr}}{2013}$} & \multicolumn{4}{|c|}{ Compression force $(\mathrm{N})$} & \multicolumn{4}{|c|}{ Skin drupelet penetration force $(\mathrm{N})$} & \multicolumn{4}{|c|}{ Receptacle penetration force $(\mathrm{N})$} \\
\hline & \multicolumn{2}{|c|}{ Crispy } & \multicolumn{2}{|c|}{ Noncrispy } & \multicolumn{2}{|c|}{ Crispy } & \multicolumn{2}{|c|}{ Noncrispy } & \multicolumn{2}{|c|}{ Crispy } & \multicolumn{2}{|c|}{ Noncrispy } \\
\hline & $13.3^{z}$ & $\mathrm{~A}^{\mathrm{y}} \mathrm{a}^{\mathrm{x}}$ & 8.2 & $\mathrm{Bc}$ & $0.29^{\mathrm{z}}$ & $\mathrm{A}^{\mathrm{y}} \mathrm{a}^{\mathrm{x}}$ & 0.17 & $\mathrm{Bb}$ & $0.27^{\mathrm{z}}$ & $\mathrm{A}^{\mathrm{y}} \mathrm{a}^{\mathrm{x}}$ & 0.22 & $\mathrm{Bc}$ \\
\hline 2014 & 10.2 & $\mathrm{Ab}$ & 7.7 & $\mathrm{Bd}$ & 0.18 & $\mathrm{Ab}$ & 0.12 & $\mathrm{Bc}$ & 0.12 & $\mathrm{Ab}$ & 0.13 & Ad \\
\hline
\end{tabular}

${ }^{\mathrm{z}}$ Values correspond to compression force, skin drupelet penetration force, and receptacle penetration force measured in Newton (N).

${ }^{\mathrm{y}}$ Means in the same row followed by the same uppercase letter are not significantly different by least square means, $P \leq 0.05$.

${ }^{\mathrm{x}}$ Means in columns followed by the same lowercase letter are not significantly different by least square means, $P \leq 0.05$.

The receptacle penetration firmness within the crispy texture among years was different. In 2013 , it was significantly higher compared with 2014 ( 0.27 and $0.12 \mathrm{~N}$, respectively), and within noncrispy texture in 2013 was significantly higher than in $2014(0.22$ and $0.13 \mathrm{~N}$, respectively) (Table 1). High temperatures in the field, rainfall before harvest, and incorrect temperature control during postharvest handling have negative impacts on blackberry fruit firmness and subsequent shelf life (Clark and Finn, 2011; Perkins-Veazie et al., 1999). According to the data obtained from the weather station of FRS during the harvest period in 2014, the amount of rain was 3.3 times higher compared with 2013. Also, during the harvest period the number of rainy days in 2013 was two and in 2014 was nine. These data support the hypothesis that environment was different between these two seasons and that the higher amount of rain in 2014 likely had a significant negative impact on fruit firmness.

Fruit morphology. Fruit morphology examination for cellular structure, using the confocal microscope, showed visual differences between crispy and noncrispy genotypes. Drupelet mesocarp cells and cell walls of the crispy selection A-2453 were visually differentiated compared with 'Natchez' (Fig. 1A and B, respectively). Cells and cell walls of 'Natchez' were not differentiated and appeared to break apart corresponding with its noncrispy texture (Fig. 1B). For 'Shawnee' (figure not shown), cellular structures (cell and cell walls) were observed in the drupelet mesocarp, but cells appeared to have more intercellular space compared with crispy genotypes, suggesting loss of cell-cell adhesion and potentially soft berries. Similar results were found by Atkinson et al. (2012) in apples when fruits of 'Royal Gala' from normal and transgenic plants [which had the endopolygalacturonase gene (a gene associated with fruit softening in apples) suppressed] were compared. The authors suggest that this loss of cell-cell adhesion could be due to disintegration of the middle lamella. The middle lamella is a pectin layer that acts as "glue" holding neighboring cells together, which contributes to the overall textural change during fruit ripening (Toivonen and Brummel, 2008). In red raspberry, it was determined that pectin is one of the key factors determining firmness and it was observed that a reduced level of pectin and methyl ester hydrolysis contributed to firm cultivars being more able to maintain cell wall cohesion (Brummell, 2006; Stewart et al., 2001). Since red raspberry and blackberry are in the same genus,
A

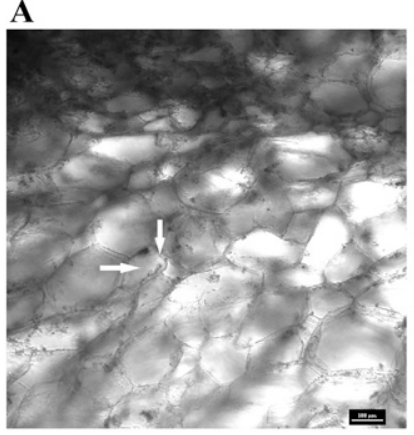

B

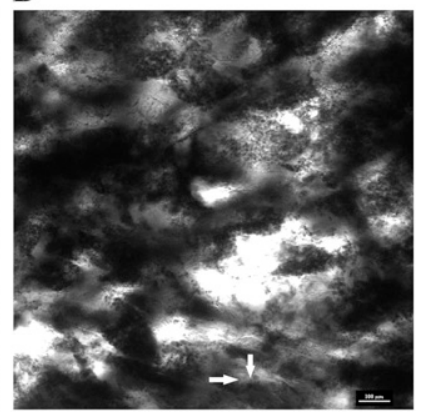

Fig. 1. Ripe drupelet mesocarp image of (A) selection A-2453 and (B) noncrispy cultivar Natchez taken by a confocal microscope. Bars $=100 \mu \mathrm{m}$. Horizontal arrow indicates an individual cell. Vertical arrow indicates cell wall/middle lamella.

these same processes may be involved in both species. In our study, the mesocarp of drupelets of crispy genotypes maintained their cell walls and cell-cell adhesion during ripening due to the complete integrity of their middle lamella. Receptacle cells of crispy genotype A-2453 (Fig. 2A) had a clear and defined structure of cells and maintained their tissue structure compared with 'Natchez' (noncrispy genotype) (Fig. 2B), in which it was very difficult to distinguish individual cells. This difference in cell structure of the receptacles was observed even when there were not significant differences in receptacle firmness between crispy and noncrispy textures in 2014 (Table 1).

Color reversion. Color reversion in blackberry fruits is a postharvest disorder with genetic and environmental influences (Clark, 2005; Clark and Finn, 2011). Drupelets expressing this disorder turn red during cold storage or after being in cold storage and exposed to room temperature (Clark and Finn, 2011; Finn and Clark, 2012). Color reversion was evaluated in 2013 and 2014 after 1 week of cold storage using a multinomial scale. The ANOVA indicated the only significant source of variation was texture $(P=0.0112)$ and nonsignificant sources were year, year by texture, genotype (texture), and year by genotype (texture).

For noncrispy genotypes, $28.0 \%$ of berries developed a "some" level of color reversion and $13.0 \%$ developed a "too many" level of this disorder (Fig. 3). Values for crispy genotypes were significantly lower than noncrispy genotypes, with $10.1 \%$ of the berries in the "some" level and 3.2\% in the "too many" level of development of this disorder. The percentage of fruits with no development or expression of this disorder after storage was
$59.0 \%$ for noncrispy genotypes and $86.8 \%$ for crispy genotypes. These results indicate that crispy genotypes have superior postharvest potential compared with noncrispy genotypes due to their low levels of color reversion development.

In a mature fruit cell, $\approx 90 \%$ of the volume is occupied by the vacuole, a cell organelle that is dynamic and multifunctional and provides the primary site of macromolecule storage and turnover (Fontes et al., 2011). The vacuole accumulates sugars, aromas, flavors, ions, and water; these compounds are transported across the tonoplast (vacuole membrane) by a specific transporter protein (Fontes et al., 2011). When the vacuole membrane is interrupted, its contents could leak into the cytoplasm changing the cytoplasmic $\mathrm{pH}$. It is possible that color reversion could be due to a breaking apart of cell membranes and cell wall, but crispy genotypes, due to their improved structure of cells, maintain the stability of their cell membranes. These genotypes likely have a reduced incidence of acid leakage into the cytoplasm. Previous studies indicated a relationship between high firmness and a decreased development of color reversion in blackberries (Perkins-Veazie et al., 1996).

\section{Conclusions}

Our study has shown that this new type of blackberry had a number of traits that contributed to the crisp texture including the 1) higher firmness of the skin and to a lesser extent the receptacle tissue, 2) ability to maintain cell wall integrity, and 3) lower levels of color reversion in storage. These traits will lead to not only the improved postharvest shelf life but also the release of a new type of blackberry to the fresh produce market. 


\section{A}

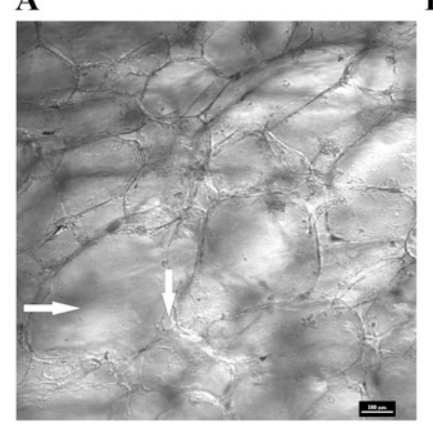

B

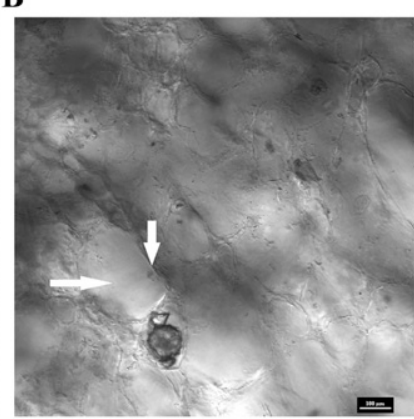

Fig. 2. Ripe receptacle image of (A) selection A-2453 and (B) noncrispy cultivar Natchez taken by a confocal microscope. Bars $=100 \mu \mathrm{m}$. Horizontal arrow indicates an individual cell. Vertical arrow indicates cell wall/middle lamella.

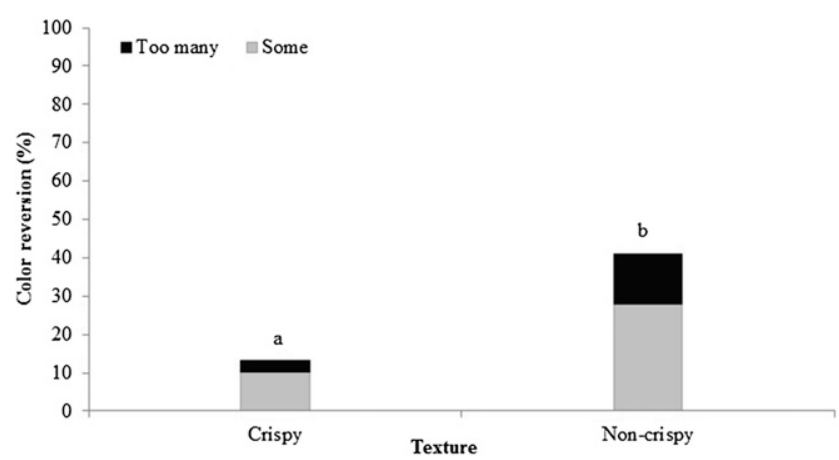

Fig. 3. Percentage of color reversion after 1 week of cold storage at $5{ }^{\circ} \mathrm{C}$ of crispy and noncrispy textures, means of years 2013 and 2014. "Some": percentage of berries showing one to three red drupelets after cold storage. "Too many": percentage of berries having more than four red drupelets after cold storage. Significant difference between textures is indicated by different letters $(P \leq 0.05)$.

Crispy genotypes had superior firmness compared with noncrispy genotypes during both years of study. Compression firmness and drupelet skin penetration were the measurements that better represented blackberry firmness in general and also the measurements that better differentiated crispy and noncrispy genotypes. Receptacle penetration was less effective in firmness differentiation, as differences were found only in 1 year (2013) between crispy and noncrispy genotypes.

Confocal image analysis of crispy and noncrispy selections/cultivars showed clear differences between both types of textures in cell characteristics. Drupelet mesocarp cells of crispy genotypes maintained their structure during the ripening process and cell walls did not break apart, compared with noncrispy genotypes where cells did not remain intact. Visual evidence indicated that noncrispy genotypes did have loss of integrity of cell walls, likely allowing the sugars and acids to be leaked. This was particularly observed for 'Natchez'.

Color reversion is considered one of the most frequent and least understood postharvest disorders of blackberry fruit. An exciting finding was that crispy genotypes after 1 week of cold storage showed lower levels of color reversion compared with noncrispy genotypes indicating higher postharvest potential.

\section{Literature Cited}

Atkinson, R., P. Sutherland, S. Johnston, K. Gunaseelan, D. Mitra, D. Brummell, R. Schröder, J. Johnston, I. Hallett, and R. Schaffer. 2012. Down-regulation of POLYGALACTURONASE1 alters firmness, tensile strength and water loss in apple (Malus x domestica) fruit. BMC Plant Biol. 12:129-141

Brummell, D. 2006. Cell wall disassembly in ripening fruit. Funct. Plant Biol. 33:103-119.

Clark, J.R. 2005. Intractable traits in eastern U.S blackberries. HortScience 40:1954-1955.
Clark, J.R. and C.E. Finn. 2011. Blackberry breding and genetics. In: H. Flachowwsky and V.-M. Hanke (eds.). Methods in temperate fruit breeding. Fruit, Veg. and Cereal Sci. and Biotechnol. 5(Spec. Issue 1):27-43.

Clark, J.R. and C.E. Finn. 2014. Blackberry cultivation in the world. Rev. Bras. Frutic. 36:46-57.

Clark, J.R. and J.N. Moore. 2008. 'Natchez' thornless blackberry. HortScience 43:1897-1899.

Clark, J.R. and P. Perkins-Veazie. 2011. 'APF-45' primocane-fruiting blackberry. HortScience 46:670-673.

Clark, J.R., E. Stafne, H. Hall, and C.E. Finn 2007. Blackberry breeding and genetics. Plant Breeding Rev., Timber Press, Portland, OR. 29:19-144.

Finn, C.E. and J.R. Clark. 2012. Blackberry, p. 151-190. In: M. Badenes and D. Byrne (eds). Fruit breeding. Springer Science + Business Media, New York.

Fontes, N., H. Geron, and S. Delrot. 2011. Grape berry vacuole: A complex and heterogeneous membrane system specialized in the accumulation of solutes. Amer. J. Enol. Viticult. 62:270-279.

Iwanami, H., S. Moriya, N. Kotoda, S. Takahashi, and K. Abe. 2008. Estimations of heritability and breeding value for postharvest fruit softening in apple. J. Amer. Soc. Hort. Sci. 133:92-99.

Perkins-Veazie, P., J. Collins, and J.R. Clark. 1996. Cultivar and maturity affect postharvest quality of fruit from erect blackberries. HortScience 31:258-261.

Perkins-Veazie, P., J. Collins, and J.R. Clark. 1999. Cultivar and storage temperature effects on the shelf-life of blackberry fruit. Fruit Var. J. 53: 201-208.

Perkins-Veazie, P., J.K. Collins, and J.R. Clark. 2000. Shelf-life and quality of 'Navaho' and 'Shawnee' blackberry fruit stored under retail storage conditions. J. Food Qual. 22:535-544.

Smith, S. 2016. Small fruit diseases. 26 Apr. 2016. <http://www.uaex.edu/publications/pdf/ mp154year2016/pg12thru23smallfruitcom.pdfs.

Stephens, M., P. Alspach, R. Beaton, C. Winefield, and E. Buck. 2012. Genetic parameters and development of a selection index for breeding red raspberries for processing. J. Amer. Soc. Hort. Sci. 137:236-242.

Stewart, D., P. Ianneta, and H. Davies. 2001 Ripening-related changes in raspberry cell wall composition and structure. Phytochemistry 56 423-428.

Strik, B., J.R. Clark, C.E. Finn, and M. Bañados 2007. Worldwide production of blackberries. Acta Hort. 777:209-217.

Toivonen, P. and D. Brummel. 2008. Biochemical bases of appearance and texture in fresh-cut fruit and vegetables. Postharvest Biol. Technol. 48:1-14.

U.S. Department of Agriculture (USDA). 2012 Plant hardiness zone map. Agricultural Research Service, U.S. Dept. Agr. 23 Jan. 2016. $<$ http://planthardiness.ars.usda.gov>.

Winkler, A., M. Ossenbrink, and M. Knoche. 2015 Malic acid promotes cracking of sweet cherry fruit. J. Amer. Soc. Hort. Sci. 140:280-287. 